\title{
BMJ Open Evolving landscape of stroke prevention in atrial fibrillation within the UK between 2012 and 2016: a cross-sectional analysis study using CPRD
}

\author{
Laure Lacoin, ${ }^{1}$ Matthew Lumley, ${ }^{2}$ Essra Ridha, ${ }^{1}$ Marta Pereira, ${ }^{3}$ Laura McDonald, ${ }^{3}$ \\ Sreeram Ramagopalan, ${ }^{3}$ Cinira Lefèvre, ${ }^{4,5}$ David Evans, ${ }^{5}$ Julian P Halcox ${ }^{6}$
}

To cite: Lacoin L, Lumley M, Ridha E, et al. Evolving landscape of stroke prevention in atrial fibrillation within the UK between 2012 and 2016 a cross-sectional analysis study using CPRD. BMJ Open 2017;7:e015363. doi:10.1136/ bmjopen-2016-015363

- Prepublication history and additional material for this paper are available online. To view these files please visit the journal online (http://dx.doi. org/10.1136/bmjopen-2016015363).

Received 1 December 2016 Revised 24 May 2017 Accepted 12 June 2017

\section{CrossMark}

${ }^{1}$ UK Medical Department, Bristol-Myers Squibb, Uxbridge, UK

${ }^{2}$ Medical Department, Pfizer, Tadworth, UK

${ }^{3}$ Real-World Evidence, Evidera, London, UK

${ }^{4}$ Center of Observational Research and Data Sciences, Business Insights and Analytics, Bristol-Myers Squibb, Rueil Malmaison, France

${ }^{5}$ Worldwide Health Economics \& Outcomes Research, BristolMyers Squibb, Rueil Malmaison, France

${ }^{6}$ Department of Cardiology,

Swansea University, Cardiff, UK

Correspondence to

Professor Julian P Halcox;

J.P.J.Halcox@swansea.ac.uk

\section{ABSTRACT}

Objective To describe the changes in prescribing of oral anticoagulant (AC) and antiplatelet (AP) agents in patients with non-valvular atrial fibrillation (NVAF) in the UK and to identify the characteristics associated with deviation from guideline-based recommendations.

Design Five cross-sectional analyses in a large

retrospective population-based cohort study.

Setting General practices contributing data to the UK Clinical Practice Research Datalink.

Participants The study included patients with a diagnosis of NVAF and eligible for anticoagulation $\left(\mathrm{CHA}_{2} \mathrm{DS}_{2}\right.$-VASc score $\geq 2$ ) on 1 April of 2012, 2013, 2014, 2015 and 1st January 2016.

Results The proportion of patients being treated with $\mathrm{AC}$ increased at each index date, showing an absolute rise of $16.7 \%$ over the study period. At the same time, the proportion of patients treated with an AP alone was reduced by half, showing an absolute decrease of $16.8 \%$. The proportion of patients not receiving any antithrombotic (AT) treatment remained the same across the study period. A number of predictors were identified for AP alone or no treatment compared with AC treatment.

Conclusion Major improvements in the AT management of patients with NVAF for stroke prevention in the UK were observed between April 2012 and January 2016. Despite this, nearly $20 \%$ of at-risk patients still received AP alone and over 15\% were on no AT agents in January 2016.

\section{INTRODUCTION}

Atrial fibrillation (AF) is the most common cardiac arrhythmia, ${ }^{1}$ estimated to affect up to 35 million people worldwide, ${ }^{2}$ with 1.4 million people affected in England alone. ${ }^{3} \mathrm{AF}$ is an independent risk factor for stroke, increasing the risk five-fold. ${ }^{4}$

Approximately $20 \%$ of stroke cases in the UK are thought to have AF as a contributing factor, and AF-related strokes are more likely to be fatal or cause severe disability than non-AF related strokes. ${ }^{5} 6$ However, AF-related strokes can be prevented and their impact minimised by effective management strategies including increased detection of
Strengths and limitations of this study

- A large representative population of patients with all forms of atrial fibrillation (paroxysmal and chronic) studied in the 'real-world' using data obtained from general practitioner records in Clinical Research Practice Datalink (CPRD)

- Real-world data are more likely to reflect wider contemporary treatment practices than information obtained from registries.

- Although CPRD is regularly and extensively audited to ensure data quality, the study is limited by the accuracy of GP records.

- The completeness of the GP record is difficult to ascertain, and we may have not detected some individuals receiving anticoagulant prescriptions in secondary care.

$\mathrm{AF}$, adherence to stroke prevention guidelines and anticoagulant (AC) use in at-risk patients.

Although AC use is effective in preventing strokes due to $\mathrm{AF}$, evidence suggests $\mathrm{AC}$ therapy remains underused. $^{7-13}$ In 2010, Holt $e t$ at showed that only $50.7 \%$ of patients with non-valvular AF (NVAF) at high risk of stroke in the UK were treated with oral AC. Opportunities to impact significantly on an important cause of cardiovascular morbidity and mortality are thereby frequently missed.

In 2012, a focused update of the 2010 European Society of Cardiology (ESC) guidelines for the management of AF was issued. ${ }^{14}$ This update included three major changes based on new or strengthened evidence. First, the $\mathrm{CHA}_{2} \mathrm{DS}_{2}$-VASc score replaced the $\mathrm{CHADS}_{2}$ score for the assessment of stroke risk. This was based on the accumulated evidence that the $\mathrm{CHA}_{2} \mathrm{DS}_{2}$-VASc score, which is inclusive of the most common risk factors for stroke $\mathrm{e}^{15}$ and has been validated in multiple cohorts, ${ }^{16}$ is better at identifying patients at "truly low 
risk' of AF-related stroke. ${ }^{17-20}$ Second, the use of aspirin therapy for stroke prevention in $\mathrm{AF}$ was restricted to those patients who refuse oral AC. Third, the use of non-vitamin K antagonist oral anticoagulants (Novel Oral ACs (NOACs) such as dabigatran, apixaban and rivaroxaban) was recommended in preference to vitamin $\mathrm{K}$ antagonists (VKAs such as warfarin) in most patients with a $\mathrm{CHA}_{2} \mathrm{DS}_{2}-$ VASc score $\geq 1 .{ }^{14}$

Despite these guidelines and the weight of evidence, national audit data from the UK showed that among patients with known AF admitted to hospital for stroke between January and March 2013, 38\% were taking antiplatelet (AP) drugs alone. ${ }^{21}$

In 2014, when the National Institute for Health and Care Excellence (NICE) updated its AF clinical guidelines (CG180), ${ }^{22}$ it recommended that NOACs should be considered as equal first-line options alongside warfarin for NVAF; furthermore, in a significant change to established practice stated that aspirin should not be used as monotherapy to prevent AF-related stroke. The Royal Colleges published a consensus statement reiterating this advice and emphasising the importance of ensuring patients are supported to make an informed choice of $\mathrm{AC}^{23}$

It is not yet known whether the update of the ESC and NICE guidelines effectively impacted treatment practices in the UK. Therefore, this study aims to describe the changes in primary care prescribing of oral AC and AP agents in patients with NVAF eligible for anticoagulation during the years 2012-2016 and to identify clinical characteristics associated with deviation from guideline-based recommendations.

\section{METHODS}

\section{Data source}

Data were obtained from the UK Clinical Practice Research Datalink (CPRD). ${ }^{24}$ The CPRD is an anonymised primary care database established in 1987 to collect longitudinal medical records data from general practitioner (GP) practices. As of April 2013, the CPRD covered 674 GP practices with 4.4 million active patients (ie, patients that are alive and registered), reflecting approximately $6.8 \%$ of the UK population. This active sample is representative of the UK population in terms of age, sex and ethnicity. The CPRD contains patient registration information as well as events that the GP records during routine clinical practice, including medical diagnoses, prescriptions issued, anthropometric measurements, diagnostic tests, lifestyle information (eg, smoking status and alcohol intake) and referrals to secondary care.

The CPRD has broad National Research Ethics Service Committee (NRES) ethics approval for purely observational research. This study protocol was approved by the Medicines and Healthcare products Regulatory Angency (MHRA) Independent Scientific Advisory Committee (protocol 14_245R).

\section{Study population}

All patients with a diagnosis of NVAF and eligible for anticoagulation according to ESC $2012^{14}$ and $\mathrm{NICE}^{23}$ guidance at index date $\left(\mathrm{CHA}_{2} \mathrm{DS}_{2}\right.$-VASc score $\left.\geq 2\right)$ were included in five cross-sectional analyses: on 1 April of 2012, 2013, 2014 and 2015 and 1 January of 2016 (index date for each year). Patients were further required to be at least 18 years old at the index date, have had at least one consultation with their GP in the last 12 months, have ongoing CPRD registration and have at least 12 months of computerised medical data prior to the index date. Patients were excluded from the study if they had a valvular condition (eg, rheumatic mitral or aortic valve disease, or prosthetic valve; codes used to identify patients are in the data supplement) or if their gender was unknown. Figure 1 summarises the patient selection process.

\section{Study variables}

Exposure to AC was defined by the last anticoagulation prescription identified in the 90-day period preceding the index date. Three type of regimens were defined: AC, AP alone or no antithrombotic (AT) treatment. AC included VKAs, apixaban, rivaroxaban, dabigatran and parenteral AC. International normalised ratio (INR) measurements were treated as an indicator of VKA exposure and used to extend VKA exposure time. Exposure to AP alone was defined by an absence of AC prescription and the presence of at least one AP prescription in the 90-day period preceding the index date. No AT was defined by the absence of AC or AP prescription in the 90-day period preceding the index data. A 90-day period has been used in previous studies to identify recent treatment exposure. ${ }^{25}$

Demographic characteristics included age, gender and country of residence. Clinical characteristics were body mass index, smoking status, time since NVAF diagnosis, stroke risk factors (previous stroke, transient ischaemic attack (TIA) or other arterial thromboembolism, congestive heart failure (CHF), coronary artery disease, peripheral artery disease, hypertension or diabetes mellitus), other bleeding risk factors (previous bleeds, peptic ulcer, renal disease, liver disease, concomitant treatment with AP or non-steroidal anti-inflammatory drugs or high alcohol intake), falls, active cancer (at least one diagnosis related to cancer in the last 12 months) and number of concomitant treatments (prescribed in the last 90 days). The $\mathrm{CHA}_{2} \mathrm{DS}_{2}$-VASc score and a modified HAS-BLED score (excluding INR component as not consistently reported in CPRD, score range: 0-8) were calculated for all patients. All clinical diagnoses were identified using Readead codes (codes lists provided in the data supplement). Diabetes and hypertension were also identified using the prescription of antidiabetic or antihypertensive treatments.

\section{Statistical analyses}

The proportion of patients treated with each regimen (AC, AP alone or no AT) and their 95\% CI were calculated 


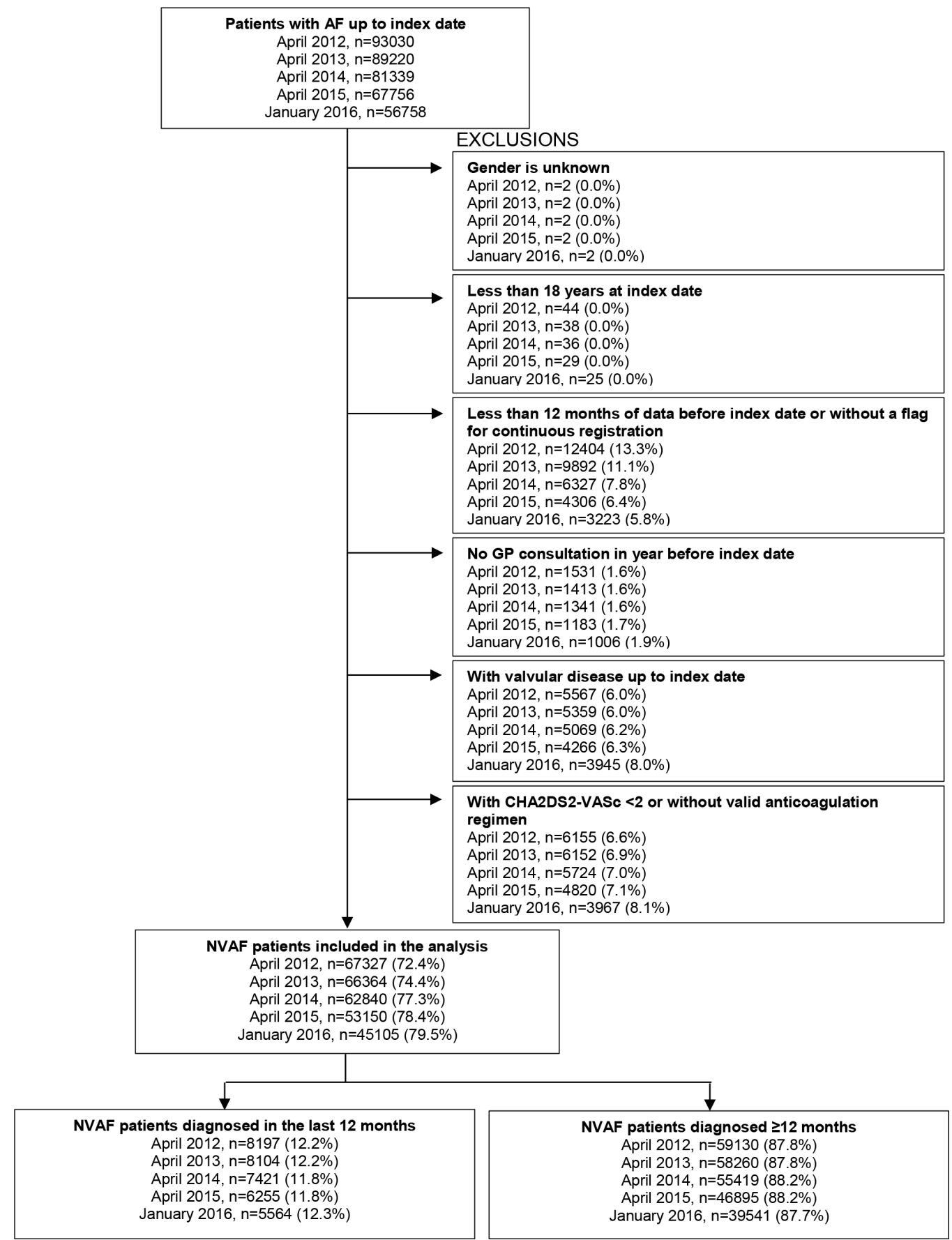

Figure 1 Flow chart describing the sample used in each year. AF, atrial fibrillation; GP, general practitioner; NVAF, non-valvular atrial fibrillation.

at each index date. As the CPRD does not provide sample survey weights, it is only possible to estimate proportions as if the CPRD data is a simple random sample of approximately $8 \%$ of UK GPs/patients, so a finite population correction factor of 0.96 was applied to the standard errors of proportion estimates $(\mathrm{FPCF}=\sqrt{ }(1-0.08) \sim 0.96)$.

An interrupted time series analysis ${ }^{26}$ was conducted to estimate the impact of the updated ESC guidance (published in August 2012) and NICE 2014 ${ }^{23}$ guidance (published in June 2014) on the evolution of the proportion of patients treated with each regimen, controlling for baseline level and trend. For this analysis, data from April
2011 to April 2015 were used, and month-by-month estimates were extracted to obtain 50 time-points (using the same inclusion criteria than for the five main cross-sectional analyses). The time series model was divided into three time periods: (1) pre-ESC guidelines, (2) post-ESC guidelines and (3) post-NICE guidelines. The statistical significance of the change in level (ie, the rapid drop in rates immediately after the intervention) and trend (ie, the gradual decline in rates over the remainder of the follow-up period) were tested for each time period. The slope in each time period was calculated by summing the change in trend observed in the time period and the 
previous slope (in first period (pre-ESC), the baseline trend was equal to the slope).

These analyses of the evolution of the AT management over time were also run separately in newly diagnosed patients with NVAF ( $<12$ months) and in patients with NVAF with a diagnosis for $\geq 12$ months, as well as in each country of residence separately (England, Scotland, Wales and Northern Ireland; results by country provided in the data supplement).

Generalised estimating equations (GEEs) were used to identify demographic and clinical characteristics associated with AP treatment and with the absence of AT treatment (vs receiving AC) in April 2015 (date of the last planned cross-sectional analysis). The final models were obtained using a backward elimination until all variables were significantly associated with the outcome $(\mathrm{p}<0.05)$. Models were adjusted for clustering within individuals and within GP practices, and results are given as ORs and $95 \%$ CIs.

\section{Sensitivity analyses}

To evaluate the proportion of patients that could have been misclassified as untreated, a sensitivity analysis was conducted, extending the exposure window used to classify patients to 180 days prior to index date. To assess the possible impact of GP sample modification, a second sensitivity analysis limiting the study sample to only those patients who were registered to a GP practice included in the CPRD throughout the study period.

All analyses were conducted using SAS software V.9.4.

\section{RESULTS}

\section{Patient characteristics}

The demographic and clinical characteristics of patients with NVAF eligible for anticoagulation according to ESC and NICE guidance $\left(\mathrm{CHA}_{2} \mathrm{DS}_{2}-\mathrm{VASc} \geq 2\right)$ from April 2012 to January 2016 are provided in table 1 . The characteristics of the population were consistent across the study period: patients' mean age was 78 years, $52.4 \%-54.3 \%$ were male and more than $50 \%$ were either overweight or obese. Almost $20 \%$ had a history of stroke or TIA, around $30 \%$ had a history of coronary artery disease and most had hypertension (>97\%). Approximately $12 \%$ had been diagnosed with NVAF within the preceding 12 months (newly diagnosed).

\section{Treatment patterns over time}

The proportion of patients being treated with AC increased each year, showing an absolute rise of $16.7 \%$ over the study period (from 50.2\% in April 2012 to $66.9 \%$ in January 2016) (table 2). At the same time, the proportion of patients treated with an AP alone was reduced by half, showing an absolute decrease of $16.8 \%$ (from $34.2 \%$ in April 2012 to 17.4\% January 2016). The proportion of patients not receiving any AT treatment remained the same across the study period, at around $15 \%$ of all patients with NVAF.
Stratifying the population by time since diagnosis identified the reduction in the proportion of patients treated with AP alone was greater in newly diagnosed patients, relative to those who had been diagnosed for $\geq 12$ months (26.8\% vs $15.4 \%$ ). In January 2016 , only $11.3 \%$ of the newly diagnosed patients were treated with AP alone (vs $18.3 \%$ of those diagnosed $\geq 12$ months). Similarly, the increase in the proportion of patients being prescribed $\mathrm{AC}$ was greater in those patients who were newly diagnosed compared with those diagnosed with NVAF for $\geq 12$ months (25.3\% vs $15.5 \%)$. In January $2016,72.5 \%$ of the newly diagnosed patients were treated with AC (vs $66.1 \%$ of those diagnosed for $\geq 12$ months).

In newly diagnosed patients, major changes in the type of oral AC prescribed were observed between April 2014 and January 2016. The proportion of patients initiated with VKA fell from $50.8 \%$ to $31.8 \%$ of all patients with NVAF, while the NOAC prescriptions rose from $9.8 \%$ to $40.6 \%$ (including $16.6 \%$ apixaban, $2.4 \%$ dabigatran and $21.5 \%$ rivaroxaban). No major change was observed in the NVAF population with a diagnosis for $\geq 12$ months; VKA was prescribed in $50.9 \%$ of the population in January 2016 and NOACs in $15 \%$ (including $4.5 \%$ apixaban, $2.2 \%$ dabigatran and $8.3 \%$ rivaroxaban).

A sensitivity analysis using a time period of 180 days prior to index date was used to evaluate the proportion of patients that could have been misclassified as untreated. This analysis provided the same results, with only $2 \%$ difference in the proportion of untreated patients observed. Results were also unchanged when restricting only to those patients who were registered to a GP included in the CPRD throughout the study period.

Impact of ESC and NICE guidelines publications on UK practice The time series analysis stratified by time since NVAF diagnosis ( $<12$ months or $\geq 12$ months) showed that there was a significant trend for increasing $\mathrm{AC}$ treatment in both patient groups since April 2011 (table 3). However, a significant acceleration of this trend (increase of the slope) was observed after the updated ESC guidance publication (change in trend: $\beta=+0.26$ in newly diagnosed, $\beta=+0.18$ in patients diagnosed $\geq 12$ months) and also after NICE guidance publication (change in trend: $\beta=+0.12$ in newly diagnosed, $\beta=+0.15$ in patients diagnosed $\geq 12$ months).

Equally, a significant trend for decreasing AP use was observed since April 2011. A significant acceleration of this trend was observed after both ESC and NICE guidance publications. This change in trend was more marked after ESC for the newly diagnosed patients (post-ESC: $\beta=-0.26$, post-NICE: $\beta=-0.10)$ and after NICE for patients diagnosed $\geq 12$ months (post-ESC: $\beta=-0.15$, post-NICE: $\beta=-0.21$ ).

\section{Characteristics associated with the absence of AC therapy in} April 2015

Tables 4 and 5 present the results of the GEE models comparing demographic and clinical characteristics in 


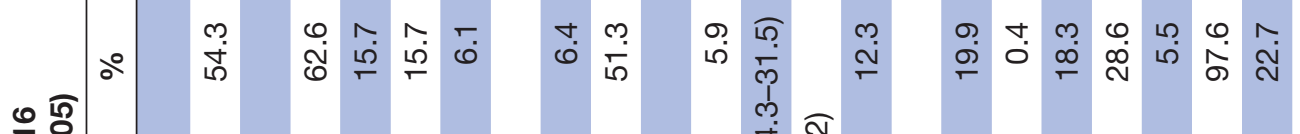

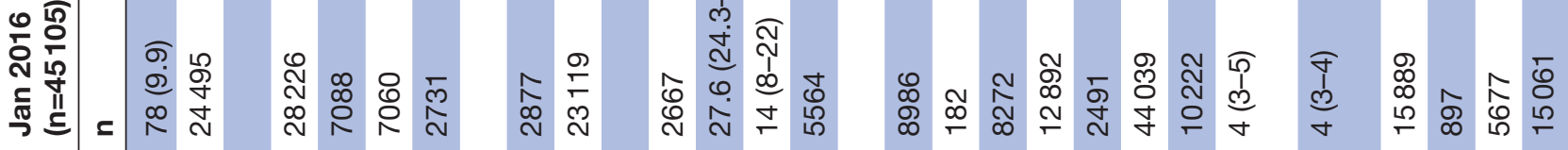

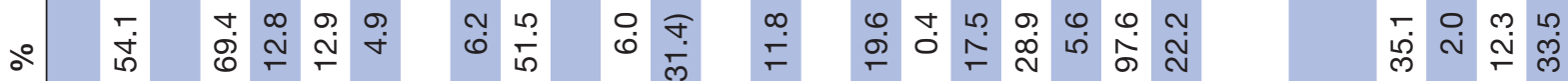

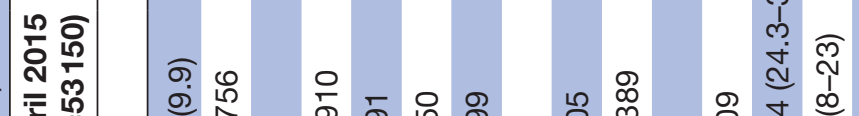

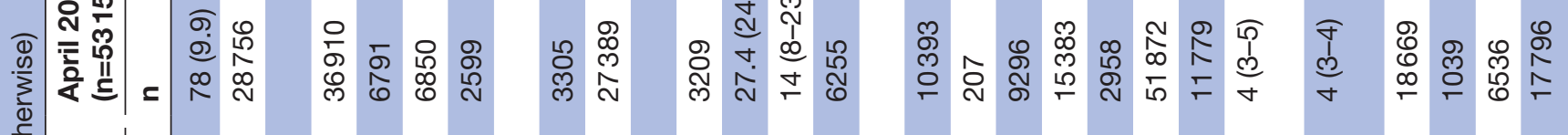

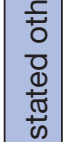

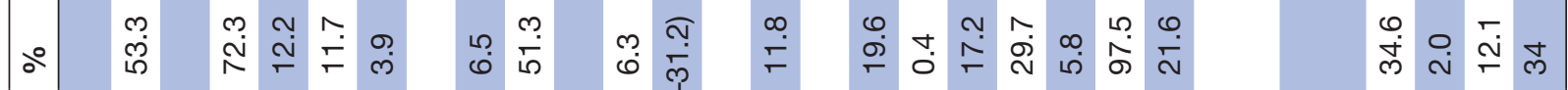

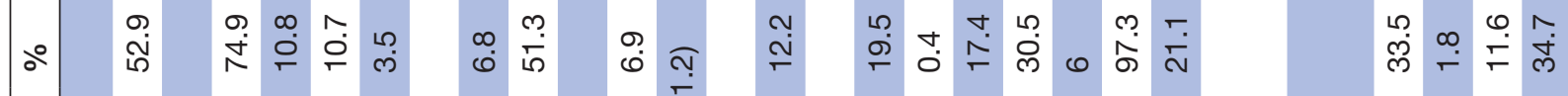

\section{商}

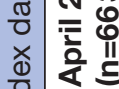

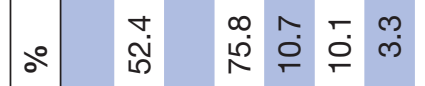

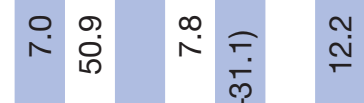

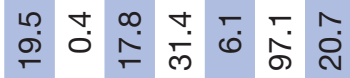

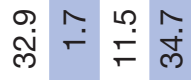

을

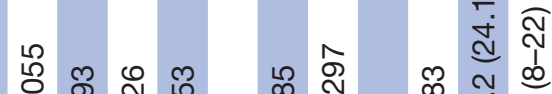

空

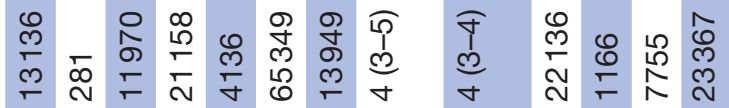
$\stackrel{\infty}{\wedge}$
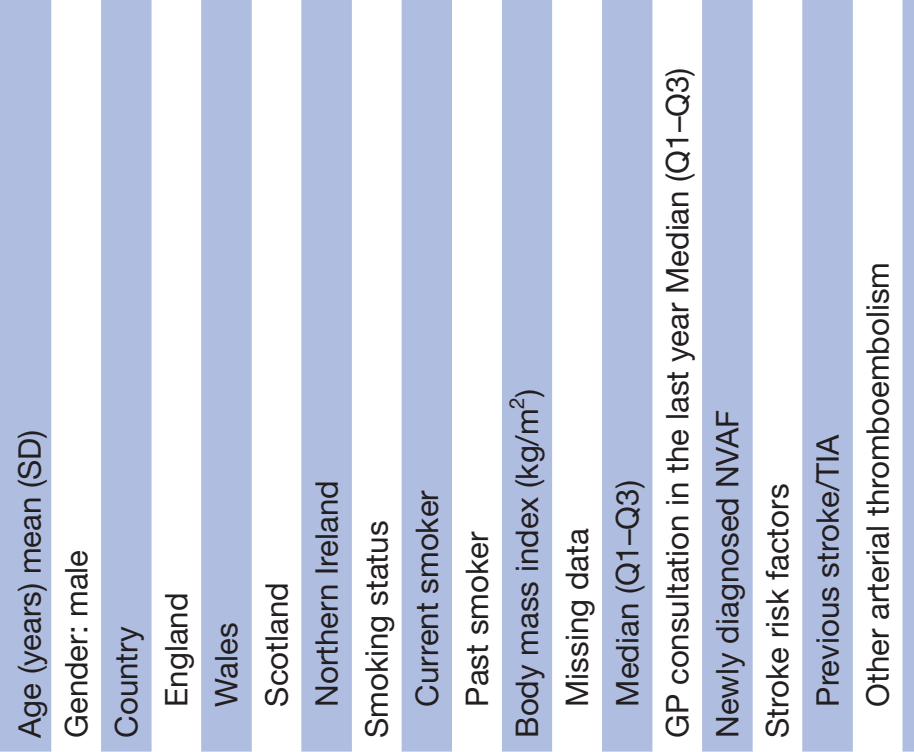

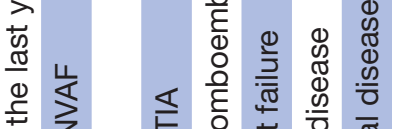

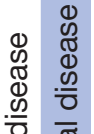

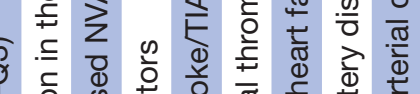

总

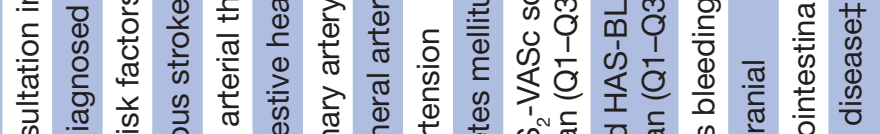

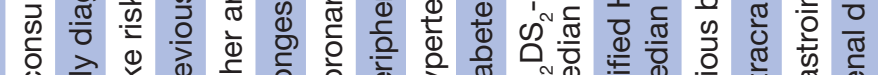

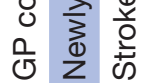




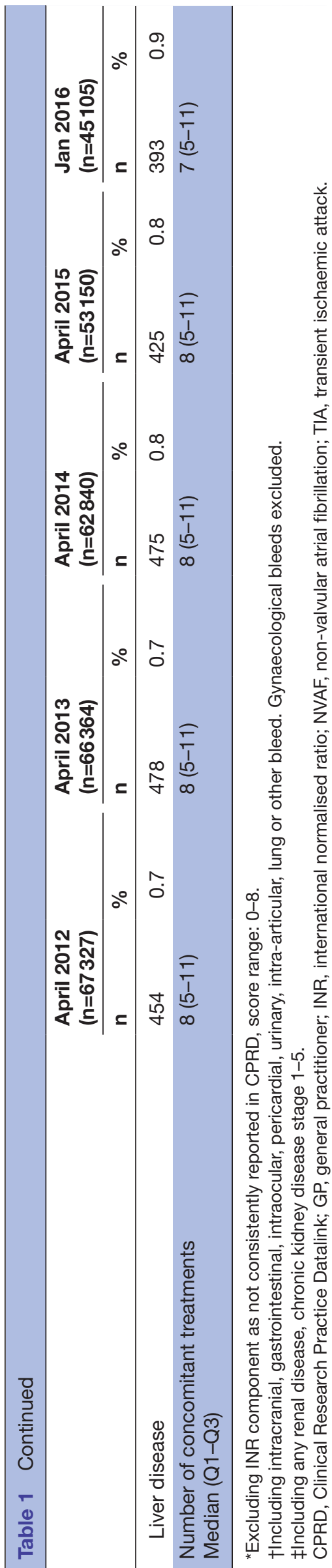

patients receiving either an $\mathrm{AP}$ alone or no AT, versus those receiving AC treatment in April 2015. Even after adjusting on $\mathrm{CHA}_{2} \mathrm{DS}_{2}$-VASc score, females and patients aged $<65$ or $\geq 85$ (vs patients $65-74$ years) were more likely to be prescribed an AP alone or no AT treatment, whereas patients with a history of stroke/TIA, CHF or hypertension were less likely to remain untreated. The likelihood of being treated with AP alone increased with time since diagnosis. Patients with coronary and peripheral artery disease were also more likely to be treated with an AP alone than AC. Importantly, $\mathrm{CHA}_{2} \mathrm{DS}_{2}-\mathrm{VASc}$ was associated with the absence of AT treatment, and patients with a score $\geq 3$ were less likely to remain untreated than patients with a $\mathrm{CHA}_{2} \mathrm{DS}_{2}$-VASc score $=2$. To less extent, the same association was observed in patients treated with AP alone (vs AC). Patients who had a previous intracranial bleed were more likely to be treated with AP and even more likely to remain untreated. The absence of any AT was more frequent in patients with less than five comedications. Geographic variations were observed, with a higher proportion receiving AP alone or no AT in England and Scotland compared with Wales and Northern Ireland.

\section{DISCUSSION}

A pronounced shift in AC management of patients with NVAF was observed in the UK between April 2012 and January 2016, coinciding with the update of $\mathrm{ESC}^{14}$ and $\mathrm{NICE}^{22}$ guidelines and with the availability of the NOACs as an alternative to VKAs. A substantial increase in the proportion of patients with NVAF at risk of stroke treated with $\mathrm{AC}$ was observed during this time (from $50.2 \%$ to $66.9 \%)$, as well as an important decrease of AP use $(34.2 \%$ to $17.4 \%$ ).

Whereas important increases in the proportion of patients with NVAF treated with AC were previously described in the UK between 1994 and 2003, ${ }^{78}$ no significant changes were observed in the years 2007-2010 in patients with $\mathrm{CHA}_{2} \mathrm{DS}_{2}-\mathrm{VASc} \geq 2$, with AC use remaining low (around $50 \%$ ) and AP alone widely used $(36 \%)$. The high use of AP until March 2012 may have also partly reflected the recommendations of the Quality and Outcomes Framework of the National Health Service (NHS), which provided equal emphasis on $\mathrm{AC}$ and $\mathrm{AP}$ in stroke prevention in primary care at that time. ${ }^{13}$

The observed shift in treatment patterns in this study suggests a positive impact of both the $\mathrm{ESC}^{14}$ and $\mathrm{NICE}^{22}$ guidelines in driving changes in thrombopropylaxis strategy for patients with NVAF in the UK, most notably the move away from AP use. The release of the ESC guidance appeared to impact more significantly the management of recently diagnosed patients. This may reflect an earlier change in the practice of cardiologists who, in the UK, are typically more involved in the diagnosis and initial management of NVAF. Indeed, the publication of the NICE guidance had a greater impact on the decline in AP use among patients with a pre-existing diagnosis, which might reflect the higher impact of local guidance 
Table 2 Evolution of the proportion of patients treated with anticoagulants, with antiplatelet therapy alone or no antithrombotic therapy among patients with NVAF with CHA2DS2-VASc $\geq 2$

\begin{tabular}{|c|c|c|c|c|c|}
\hline & $\begin{array}{l}\text { April } 2012 \\
\%(95 \% \mathrm{Cl})\end{array}$ & $\begin{array}{l}\text { April } 2013 \\
\%(95 \% \mathrm{Cl})\end{array}$ & $\begin{array}{l}\text { April } 2014 \\
\%(95 \% \mathrm{Cl})\end{array}$ & $\begin{array}{l}\text { April } 2015 \\
\%(95 \% \mathrm{Cl})\end{array}$ & $\begin{array}{l}\text { January } 2016 \\
\%(95 \% \mathrm{Cl})\end{array}$ \\
\hline Anticoagulation & 50.2 (49.8 to 50.5$)$ & 53.2 (52.8 to 53.5 ) & 57.5 (57.1 to 57.9$)$ & 62.9 (62.5 to 63.3$)$ & 66.9 (66.5 to 67.3$)$ \\
\hline $\begin{array}{l}\text { Antiplatelet therapy } \\
\text { alone }\end{array}$ & 34.2 (33.9 to 34.5$)$ & 31.2 (30.8 to 31.5$)$ & 27.7 (27.3 to 28.0$)$ & 21.8 (21.5 to 22.2$)$ & 17.4 (17.1 to 17.8$)$ \\
\hline $\begin{array}{l}\text { No antithrombotic } \\
\text { therapy }\end{array}$ & 15.6 (15.4 to 15.9$)$ & 15.7 (15.4 to 15.9$)$ & 14.8 (14.6 to 15.1$)$ & 15.3 (15.0 to 15.6$)$ & 15.7 (15.4 to 16.0$)$ \\
\hline
\end{tabular}

on GPs who are more involved in the long-term management of patients.

Overall, the most marked improvement in stroke prevention in $\mathrm{AF}$ occurred in newly diagnosed patients, in whom AC prescriptions rose from $47.2 \%$ to $72.5 \%$ and the use of AP alone dropped to $11.3 \%$ in January 2016. At the time of diagnosis, patients are likely to be particularly engaged with their condition, more likely to be booked for further clinical assessment and physicians are obligated to make a decision regarding AC. Conversely, patients with a long-standing diagnosis may be more resistant to changes in their treatment regimen, and thromboembolism prophylaxis may not be the focus of clinical appointments. As newly diagnosed patients represent only $20 \%$ of the NVAF population, this emphasises the potential impact on stroke prevention in the UK that could be achieved by effectively addressing thromboembolism prophylaxis strategy in patients with an established NVAF diagnosis. Ongoing educational activity and the use of specialist nurses and pharmacist-led anticoagulation

Table 3 Time series analysis describing the trends in the evolution of the proportion of patients with NVAF treated with anticoagulants, aspirin or other AP therapy alone or without any antithrombotic treatment from April 2012 to April 2015 in the UK by time since NVAF diagnosis

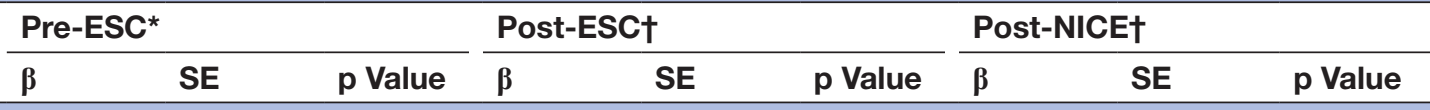

A. Anticoagulation treatment

Diagnosed $<12$ months

\begin{tabular}{|crrrrrrrrrr} 
Level & 43.09 & 0.26 & $<0.0001$ & 0.28 & 0.35 & 0.418 & 0.10 & 0.49 & 0.846 \\
\hline Trend & 0.34 & 0.02 & $<0.0001$ & 0.26 & 0.03 & $<0.0001$ & 0.12 & 0.09 & 0.171 \\
Diagnosed $\geq 12$ months & & & & & & & & & \\
$\quad$ Level & 49.01 & 0.07 & $<0.0001$ & 0.00 & 0.10 & 0.981 & -0.16 & 0.14 & 0.251 \\
\hline Trend & 0.13 & 0.01 & $<0.0001$ & 0.18 & 0.01 & $<0.0001$ & 0.15 & 0.02 & $<0.0001$
\end{tabular}

B. Aspirin (ASA) or other AP only

Diagnosed $<12$ months

$\begin{array}{llllllllll}\text { Level } & 41.94 & 0.24 & <0.0001 & -0.20 & 0.31 & 0.518 & -0.63 & 0.44 & 0.159 \\ \text { Trend } & -0.36 & 0.02 & <0.0001 & -0.26 & 0.03 & <0.0001 & -0.10 & 0.08 & 0.226\end{array}$

Diagnosed $\geq 12$ months

$\begin{array}{lccccccccc}\text { Level } & 35.05 & 0.06 & <0.0001 & 0.03 & 0.08 & 0.737 & -0.33 & 0.12 & 0.008 \\ \text { Trend } & -0.12 & 0.01 & <0.0001 & -0.15 & 0.01 & <0.0001 & -0.21 & 0.02 & <0.0001\end{array}$

C. Without any antithrombotic treatment

Diagnosed $<12$ months

\begin{tabular}{lrlrrrrrrrr} 
Level & 14.97 & 0.15 & $<0.0001$ & -0.08 & 0.19 & 0.6835 & 0.54 & 0.27 & 0.057 \\
$\quad$ Trend & 0.02 & 0.01 & 0.211 & 0.00 & 0.02 & 0.9262 & -0.03 & 0.05 & 0.612 \\
$\begin{array}{l}\text { Diagnosed } \geq 12 \text { months } \\
\text { Level }\end{array}$ & & & & & & & & & \\
Trend & 15.94 & 0.07 & $<0.0001$ & -0.03 & 0.10 & 0.789 & 0.49 & 0.14 & 0.001 \\
\hline
\end{tabular}

${ }^{*}$ Pre-ESC data are base level, base trend.

†Post-ESC and post-NICE data are change in level, change in trend.

AP, antiplatelet; ESC, European Society of Cardiology; NICE, National Institute for Health and Care Excellence; NVAF, non-valvular atrial fibrillation. 


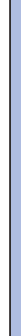

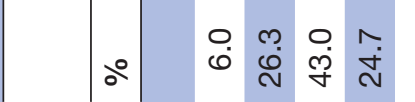

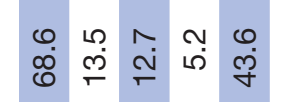

ஸ艹

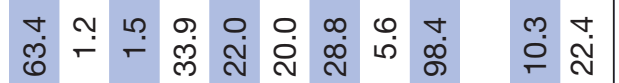




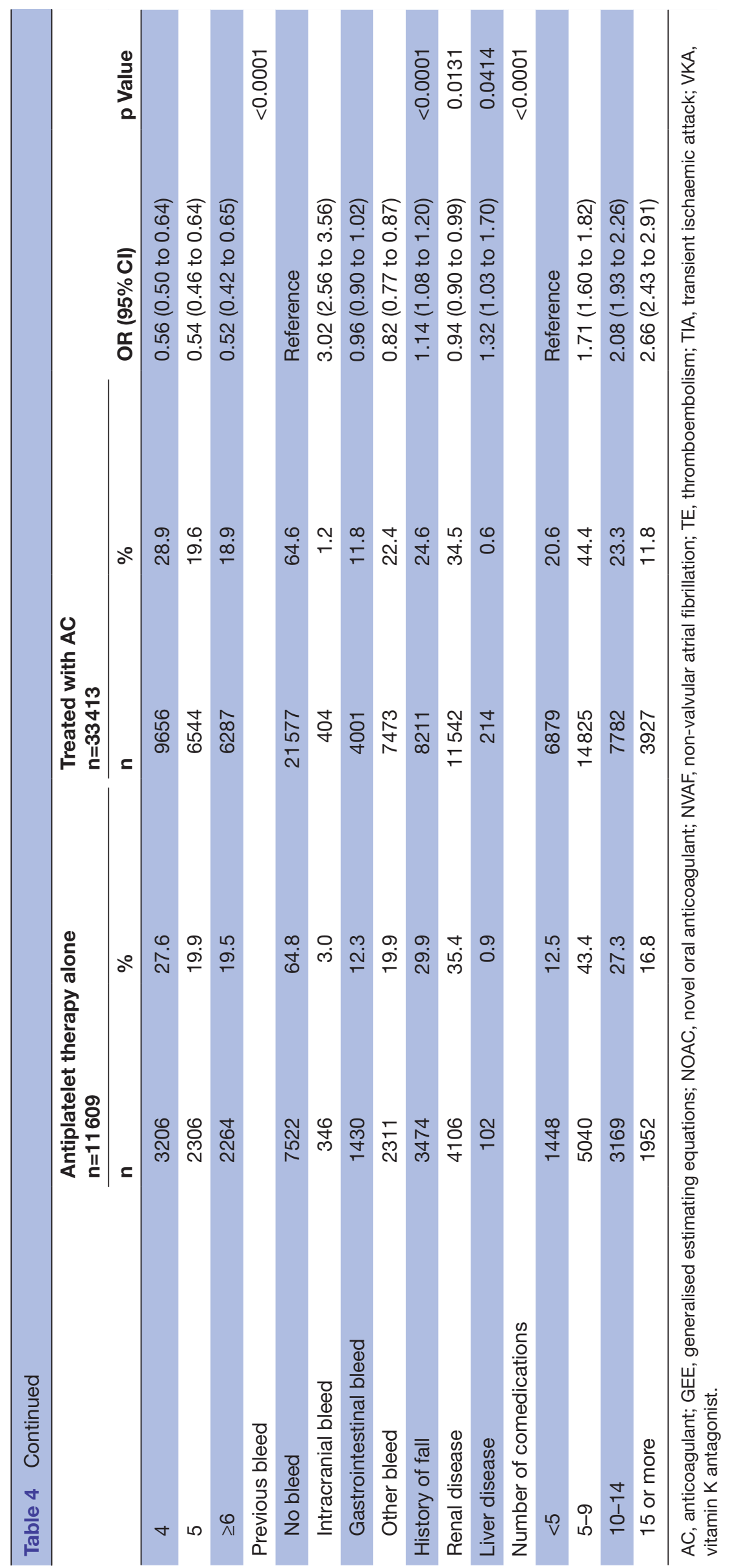

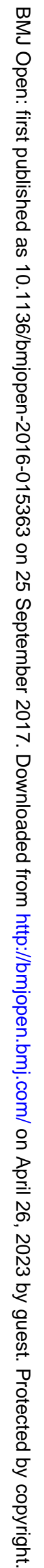




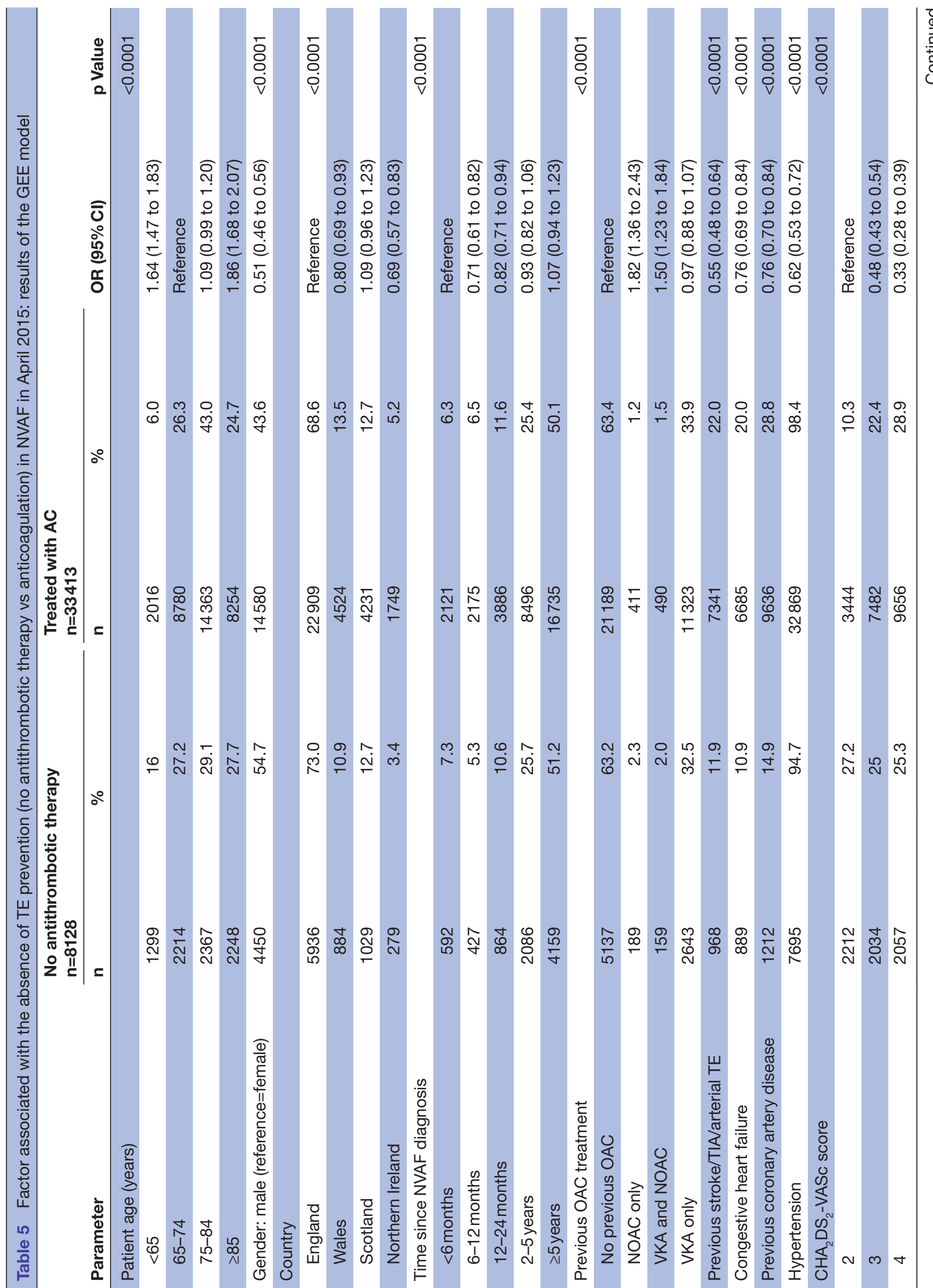




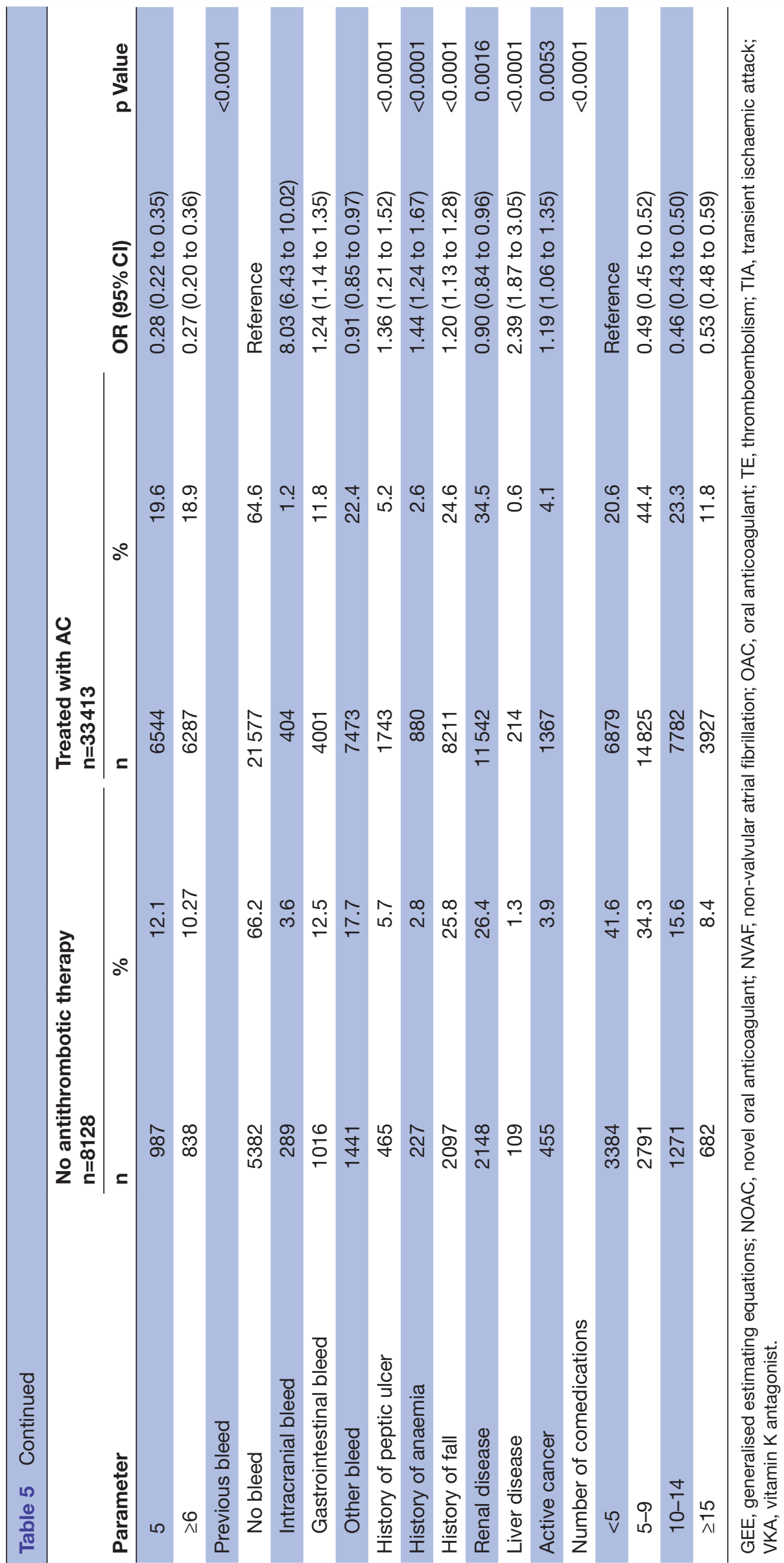


clinics will play an important role in reaching this group of patients.

Importantly, the trend for increasing use of AC between 2012 and 2016 was associated with the growing use of NOACs (apixaban, rivaroxaban and dabigatran). This growth of NOAC use was mainly observed in newly diagnosed patients between 2014 and 2016, associated with a decrease of VKA initiation and coincided with the release of NICE guidance ${ }^{22}$ and the Consensus Statement reiterating that NICE-approved treatments have to be made available for prescribing. This highlights the vital role of the NOACs as alternatives to VKA through addressing some of the limitations of VKA therapy and responding to individual patient needs. However, in patients who had been diagnosed for $\geq 12$ months, no major changes in the proportion treated with VKA were observed, indicating significant VKA inertia in this group.

This growing trend in the use of NOACs in newly diagnosed patients with AF can be linked to a growing awareness raised through NICE guidance about the benefits of NOAC treatment and to an increased attentiveness to AF detection. Currently, only opportunistic screening for AF is implemented: NICE recommends an ECG to diagnose $\mathrm{AF}$ in patients who present with irregular pulse. ${ }^{22} \mathrm{An}$ expansion in AF screening would potentially result in the earlier detection of $\mathrm{AF}$ in asymptomatic patients and thus the early provision of prophylactic OAC treatment.

Although these data show that AC treatment patterns in NVAF have improved substantially over the last 5 years, rates of anticoagulation appear to lag behind those observed in contemporary European cohorts. For example, at the 2-year follow-up of the EurObservational Research Programme - Atrial Fibrillation (EORP-AF) registry in 2015, 79.2\% of patients with $\mathrm{AF}$ were identified as receiving at least one oral AC (compared with $62.9 \%$ in 2015 in this study, table 2). ${ }^{27}$ Rates of NOAC use however appear more comparable, with $13.7 \%$ of patients in EORP-AF receiving at least one NOAC (compared with $10.9 \%$ in this study in 2015). Baseline data from the European population of the Global Registry on Long-Term Oral Antithrombotic Treatment in Patients with Atrial Fibrillation (GLORIA-AF) registry, which includes only newly diagnosed AF patients, showed the majority $(52.4 \%)$ were treated with NOACs, while $5.7 \%$ received AP therapy and only $4.1 \%$ remained untreated. ${ }^{28}$ These data are comparable with the $9.8 \%$ receiving NOACs, $23.8 \%$ AP therapy and $15.2 \%$ untreated among patients diagnosed between 2013 and 2014 in our study (figure 2). Similarly, in the global Global Anticoagulant Registry in the Field Atrial Fibrillation (GARFIELD-AF) registry of patients with very recently diagnosed NVAF ( $<6$ weeks), over the period from $2010 / 2011$ to $2014 / 2015$, the proportion of patients treated with AC increased from $57.4 \%$ to $71.1 \%$ including a significant increase in the proportion receiving NOACs (4.2\%-37.0\%), while AP monotherapy declined from $30.2 \%$ to $16.6 \% .^{29}$ It is encouraging that our data up to January 2016 continue to show AC use is increasing in the UK. Differences with European-based cohorts may, therefore, reflect a time lag associated with the later release of
NICE guidance in $2014^{22}$ relative to the ESC guidance in 2012. ${ }^{14}$ Other factors may also be involved. The time lag between guideline recommendation and routine clinical practice should be considered with the release of newer ESC guidance in 2016. ${ }^{30}$

Whereas the striking decrease of AP use observed in this study is encouraging, the absence of any changes in the proportion of patients remaining untreated raises some concerns. These current data identify patient characteristics associated with remaining untreated. Younger patients $(<65$ years), patients taking fewer prescription medications $(<5)$ and those with a $\mathrm{CHA}_{2} \mathrm{DS}_{2}$-VASc score of 2 were all more likely to remain untreated. We hypothesise that this could be secondary to a misperception of stroke risk by clinicians, but it may also be secondary to patient attitude. Furthermore for those patients $<65$ years of age, the monitoring requirements of VKAs may be regarded as incompatible with a working life, a barrier that could be overcome with the use of NOACs.

At the other end of the spectrum, elderly patients ( $>85$ years) were found to be less likely to be prescribed AC therapy and more likely to be treated with AP alone. This observation is well documented ${ }^{812} 1331-35$ and may be secondary to an overestimation of bleeding risk despite unequivocal evidence of the benefits of $\mathrm{AC}$ in the elderly. $^{36-39}$

Our findings clearly illustrate the risk-treatment paradox previously reported in $\mathrm{AF}$ management ${ }^{12}$ that patients at higher risk of stroke who are more likely to benefit from AC therapy ${ }^{38}$ are not receiving appropriate treatment, perhaps because of a perceived increased risk of bleeding. In fact, several bleeding risk factors such as falls, peptic ulcer disease, anaemia and previous risk of intracranial or gastrointestinal bleeds were found to also be associated with an increasing likelihood of remaining untreated. A survey of UK general practices from 2000 to 2009 showed that this underuse of AC therapy in the elderly is not adequately explained by either an increase in comorbidities or bleeding risk. ${ }^{40}$

In addition to age, female patients were found less likely to be treated with AC. This sex difference in prescribing has been previously observed in a UK study in $\mathrm{AF}^{8}$ Given that women with $\mathrm{AF}$ appear to lose their protection against sudden death including stroke ${ }^{41}$ and may even have a higher mortality than men, ${ }^{42}$ these lower $\mathrm{AC}$ rates are a cause for concern. AP alone was found to be prescribed more frequently in patients with coronary artery disease. This may highlight the lack of a definitive evidence base and clear guidance on the AT management of these patients, particularly in the initial period following an acute coronary syndrome.

Collectively, the results indicate a strong mandate to change current clinical practice to improve prescribing patterns among treating clinicians. This is further emphasised by the 2016 ESC guidelines, which state that aspirin monotherapy should not be used for stroke prevention in patients with AF regardless of stroke risk and may in fact cause harm. ${ }^{30}$ Although the present study was conducted 

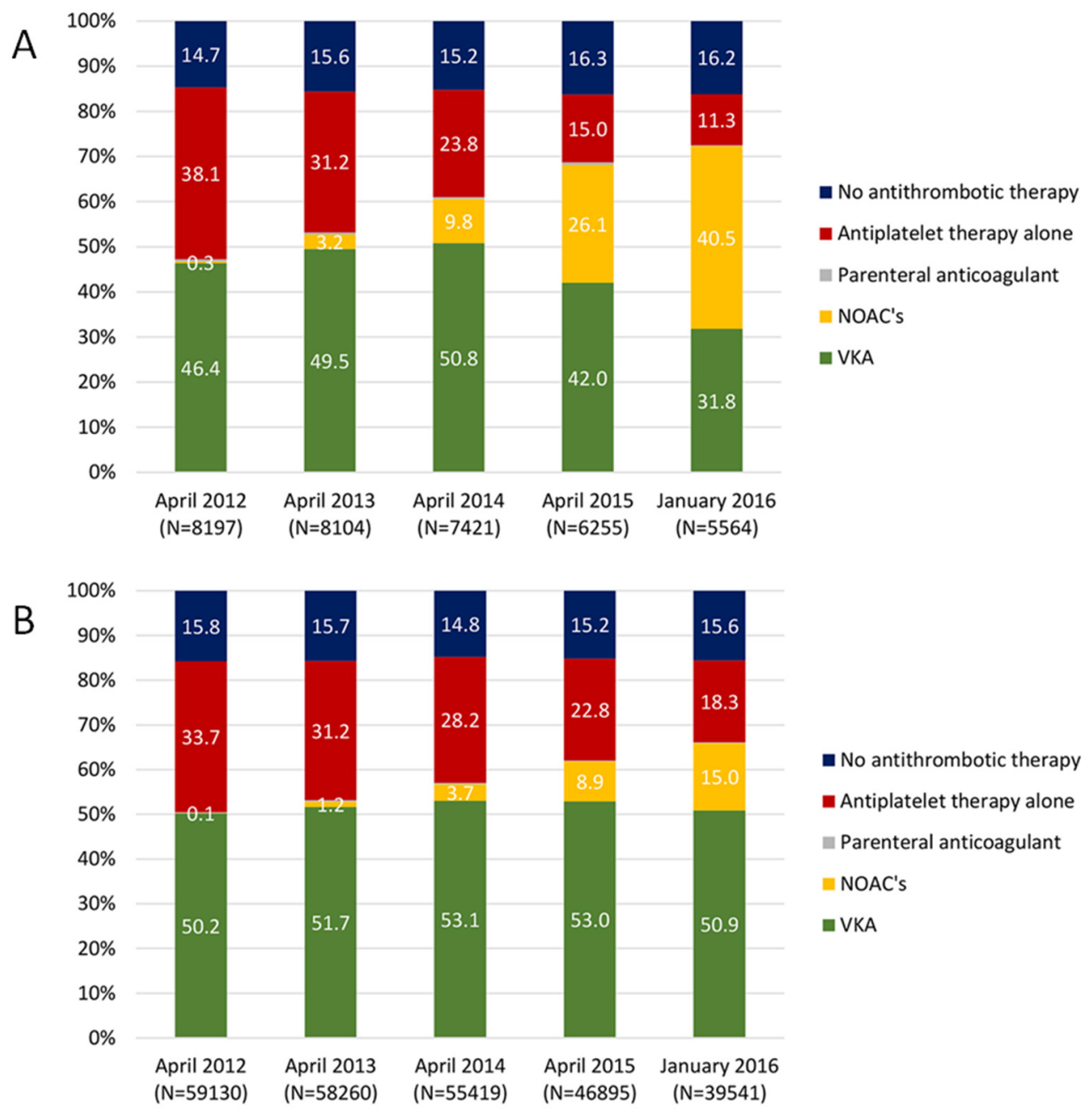

Figure 2 Evolution of the proportion of patients treated with each anticoagulant, with antiplatelet therapy alone or no antithrombotic therapy among patients with NVAF with $\mathrm{CHA}_{2} \mathrm{DS}_{2}-\mathrm{VASC} \geq 2$ separately in newly diagnosed patients (A) and patients diagnosed since 12 months or more (B). NOACs, novel oral anticoagulants; VKAs, vitamin K antagonists.

in the UK, the finding that a considerable number of patients with $\mathrm{AF}$ continue to be undertreated has wider implications for stroke prevention in $\mathrm{AF}$, which remains a global issue.

\section{Strengths and limitations}

This is a large study of a representative population of patients with NVAF managed in the UK. It includes patients with all forms of AF, including paroxysmal and chronic. The study may have not detected some individuals receiving $\mathrm{AC}$ prescriptions in secondary care. The National Patient Safety Agency has emphasised the importance of good communication between different bodies sharing responsibility for prescribing potentially interacting medication, and this has increased the use of codes in primary care to maintain awareness of AC therapy prescribed elsewhere. ${ }^{9}{ }^{3}$

This study is based on a general practice database and is limited by the accuracy of GP records. Validation of the CPRD has shown high positive predictive value of some diagnoses and, where evaluated, comparisons of incidence with other UK data sources are also broadly similar. ${ }^{44}$
However, the completeness of the record is more difficult to ascertain. We acknowledge that the results reported in this study may under-represent comorbidities and, hence, overall stroke risk.

It is important to note that due to the falling number of GP practices involved in the CRPD, the number of eligible patients with NVAF also fell during the study period. However, a sensitivity analysis was conducted on the NVAF population who were registered to a GP practice included in the CPRD throughout the study period, and the results were unchanged. Therefore, the observed change in AT management cannot be attributed to the reduction in available GP data.

It is important to reflect on the differences in the nature of data collection and analysis between registry and real world healthcare records, whereby participation in a registry may influence treatment selection but allow more complete and accurate data collection, whereas real world datasets allow analysis of much larger cohorts that are more likely to reflect wider contemporary practice, although with less complete and well-validated data. 


\section{CONCLUSION}

Major improvements in the AC management of patients with NVAF for stroke prevention in the UK were observed between April 2012 and January 2016. Despite this, 20\% of the at-risk population were still treated with AP alone and more than $15 \%$ of patients were on no AT agents in January 2016. However, if the trend of rapid reduction of AP use observed during the study period continues, then the use of AP alone for stroke prevention could essentially disappear in the next few years in the UK. The consistency observed over time in the proportion of patients not treated with any AT therapy represents the area of greatest concern. The clinical inertia seen in this group may be due to an underestimate of the risk of stroke in these patients who were found to be younger with less comorbidities, and the overestimation of bleeding risk in the elderly (>85 years). There remains a huge potential for reducing the stroke risk of the AF population by improving the thromboembolic risk assessment in NVAF in primary care and the identification of patients requiring AC.

Acknowledgements The authors would like to gratefully acknowledge the contribution of Sharon MacLachlan, Robert Donaldson and Jack Ishak who all provided expert opinion during the data analysis.

Contributors LL conceived and designed the study, contributed to the analysis and interpretation of the data and wrote the first draft of the paper as well as contributing to the final paper. CL conceived and designed the study, contributed to the analysis and interpretation of the data and contributed to the final paper. $\mathrm{DE}$ and JPH conceived and designed the study, contributed to the analysis and interpretation of the data and contributed to the final paper. LM undertook the data analysis, contributed to the interpretation of the data, wrote the first draft and contributed to the final paper. MP and SR undertook the data analysis and contributed to the interpretation of the data as well as contributing to the final paper. ML and ER contributed to the interpretation of the data and contributed to the final paper. All authors approved the final paper and have accepted accountability for all aspects of the work.

Funding This manuscript was fully funded by Bristol-Myers Squibb.

Competing interests MP, LM and SR were employees of Evidera and who were paid consultants to Bristol-Myers Squibb (BMS) in connection with conducting this study and with the development of this manuscript. JPH received consultancy fees from BMS for the conduct of this study. DE, ER, CL and LL were BMS employees at the time of the research. ML is a full-time employee of Pfizer.

Provenance and peer review Not commissioned; externally peer reviewed. Data sharing statement No additional data are available.

Open Access This is an Open Access article distributed in accordance with the Creative Commons Attribution Non Commercial (CC BY-NC 4.0) license, which permits others to distribute, remix, adapt, build upon this work non-commercially, and license their derivative works on different terms, provided the original work is properly cited and the use is non-commercial. See: http://creativecommons.org/ licenses/by-nc/4.0/

(c) Article author(s) (or their employer(s) unless otherwise stated in the text of the article) 2017. All rights reserved. No commercial use is permitted unless otherwise expressly granted.

\section{REFERENCES}

1. Go AS, Hylek EM, Phillips KA, et al. Prevalence of diagnosed atrial fibrillation in adults: national implications for rhythm management and stroke prevention: the AnTicoagulation and Risk Factors in Atrial Fibrillation (ATRIA) Study. JAMA 2001;285:2370-5.

2. Chugh SS, Havmoeller R, Narayanan K, et al. Worldwide epidemiology of atrial fibrillation: a Global Burden of Disease 2010 Study. Circulation 2014;129:837-47.
3. England PH. Atrial fibrillation prevalence estimates in England: application of recent population estimates of AF in Sweden. 2015;2015 http://www.yhpho.org.uk//resource/view.aspx?RID= 207902

4. Kirchhof P, Auricchio A, Bax J, et al. Outcome parameters for trials in atrial fibrillation: executive summary. Eur Heart J 2007;28:2803-17.

5. Royal College of Physicians. Sentinel Stroke National Audit Programme (SSNAP). Clinical audit April - June 2015 report prepared by Royal College of Physicians, Clinical Effectiveness and Evaluation Unit on behalf of the Intercollegiate Stroke Working Party. 2015.

6. Lin HJ, Wolf PA, Kelly-Hayes M, et al. Stroke severity in atrial fibrillation. The Framingham Study. Stroke 1996;27:1760-4.

7. Majeed A, Moser K, Carroll K. Trends in the prevalence and management of atrial fibrillation in general practice in England and Wales, 1994-1998: analysis of data from the general practice research database. Heart 2001;86:284-8.

8. DeWilde S, Carey IM, Emmas C, et al. Trends in the prevalence of diagnosed atrial fibrillation, its treatment with anticoagulation and predictors of such treatment in UK primary care. Heart 2006;92:1064-70.

9. Holt TA, Hunter TD, Gunnarsson C, et al. Risk of stroke and oral anticoagulant use in atrial fibrillation: a cross-sectional survey. $\mathrm{Br} \mathrm{J}$ Gen Pract 2012;62:710-7.

10. Ogilvie IM, Newton N, Welner SA, et al. Underuse of oral anticoagulants in atrial fibrillation: a systematic review. Am J Med 2010;123:638-45e634-45.

11. Nieuwlaat R, Capucci A, Lip GY, et al. Antithrombotic treatment in real-life atrial fibrillation patients: a report from the Euro Heart Survey on Atrial Fibrillation. Eur Heart J 2006;27:3018-26.

12. Sandhu RK, Bakal JA, Ezekowitz JA, et al. Risk stratification schemes, anticoagulation use and outcomes: the risk=treatment paradox in patients with newly diagnosed non-valvular atrial fibrillation. Heart 2011;97:2046-50.

13. Cowan C, Healicon R, Robson I, et al. The use of anticoagulants in the management of atrial fibrillation among general practices in England. Heart 2013;99:1166-72.

14. Camm AJ, Lip GY, De Caterina R, et al. 2012 focused update of the ESC Guidelines for the management of atrial fibrillation: an update of the 2010 ESC Guidelines for the management of atrial fibrillationdeveloped with the special contribution of the European Heart Rhythm Association. Europace 2012;14:1385-413.

15. Lip GY, Nieuwlaat R, Pisters R, et al. Refining clinical risk stratification for predicting stroke and thromboembolism in atrial fibrillation using a novel risk factor-based approach: the euro heart survey on atrial fibrillation. Chest 2010;137:263-72.

16. Lip GY. Stroke in atrial fibrillation: epidemiology and thromboprophylaxis. J Thromb Haemost 2011;9(Suppl 1):344-51.

17. Potpara TS, Polovina MM, Licina MM, et al. Reliable identification of "truly low" thromboembolic risk in patients initially diagnosed with "Ione" atrial fibrillation: the Belgrade atrial fibrillation study. Circ Arrhythm Electrophysiol 2012;5:319-26.

18. Olesen JB, Torp-Pedersen C, Hansen ML, et al. The value of the CHA2DS2-VASc score for refining stroke risk stratification in patients with atrial fibrillation with a CHADS2 score 0-1: a nationwide cohort study. Thromb Haemost 2012;107:1172-9.

19. Van Staa TP, Setakis E, Di Tanna GL, et al. A comparison of risk stratification schemes for stroke in 79,884 atrial fibrillation patients in general practice. J Thromb Haemost 2011;9:39-48.

20. Abu-Assi E, Otero-Raviña F, Allut Vidal G, et al. Comparison of the reliability and validity of four contemporary risk stratification schemes to predict thromboembolism in non-anticoagulated patients with atrial fibrillation. Int J Cardiol 2013;166:205-9.

21. Royal College of Physicans. Sentinel Stroke National Audit Programme (SSNAP). Clinical audit first pilot public report 2013.

22. National Clinical Guideline Centre. Atrial fibrillation: the management of atrial fibrillation. Clinical guideline: methods, evidence and recommendations [NICE CG180]. 2014.

23. NICE Implementation Collaborative. Consensus supporting local implementation of NICE guidance on use of the novel (non-Vitamin K antagonist) oral anticoagulants in non-valvular atrial fibrillation. 2014.

24. Herrett E, Gallagher AM, Bhaskaran K, et al. Data Resource Profile: Clinical Practice Research Datalink (CPRD). Int J Epidemiol 2015;44:827-36.

25. Gallagher AM, van Staa TP, Murray-Thomas T, et al. Populationbased cohort study of warfarin-treated patients with atrial fibrillation: incidence of cardiovascular and bleeding outcomes. BMJ Open 2014;4:e003839.

26. Penfold RB, Zhang F. Use of interrupted time series analysis in evaluating health care quality improvements. Acad Pediatr 2013;13:S38-44. 
27. Bassand JP, Accetta G, Camm AJ, et al. Two-year outcomes of patients with newly diagnosed atrial fibrillation: results from GARFIELD-AF. Eur Heart J 2016;37:2882-9.

28. Huisman MV, Rothman KJ, Paquette M, et al. Antithrombotic Treatment Patterns in Patients with Newly Diagnosed Nonvalvular Atrial Fibrillation: The GLORIA-AF Registry, Phase II. Am J Med 2015;128:1306-13e1301-13.

29. Camm AJ, Accetta G, Ambrosio G, et al. Evolving antithrombotic treatment patterns for patients with newly diagnosed atrial fibrillation. Heart 2017:103.

30. Kirchhof P, Benussi S, Kotecha D, et al. ESC Guidelines for the management of atrial fibrillation developed in collaboration with EACTS. Eur Heart J 2016;2016:2893-962.

31. Friberg L, Hammar N, Ringh M, et al. Stroke prophylaxis in atrial fibrillation: who gets it and who does not? Report from the Stockholm Cohort-study on Atrial Fibrillation (SCAF-study). Eur Heart J 2006;27:1954-64.

32. Waldo AL, Becker RC, Tapson VF, et al. Hospitalized patients with atrial fibrillation and a high risk of stroke are not being provided with adequate anticoagulation. J Am Coll Cardiol 2005;46:1729-36.

33. Gallagher AM, Rietbrock S, Plumb J, et al. Initiation and persistence of warfarin or aspirin in patients with chronic atrial fibrillation in general practice: do the appropriate patients receive stroke prophylaxis? J Thromb Haemost 2008;6:1500-6.

34. Leizorovicz A, Cohen A, Guenoun M, et al. Influence of age on the prescription of vitamin $\mathrm{K}$ antagonists in outpatients with permanent atrial fibrillation in France. Pharmacoepidemiol Drug Saf 2007;16:32-8.

35. Simpson CR, Wilson C, Hannaford PC, et al. Evidence for age and sex differences in the secondary prevention of stroke in Scottish primary care. Stroke 2005;36:1771-5.
36. Mant J, Hobbs FD, Fletcher $\mathrm{K}$, et al. Warfarin versus aspirin for stroke prevention in an elderly community population with atrial fibrillation (the Birmingham Atrial Fibrillation Treatment of the Aged Study, BAFTA): a randomised controlled trial. Lancet 2007:370:493-503.

37. Rash A, Downes T, Portner R, et al. A randomised controlled trial of warfarin versus aspirin for stroke prevention in octogenarians with atrial fibrillation (WASPO). Age Ageing 2007;36:151-6.

38. van Walraven C, Hart RG, Connolly S, et al. Effect of age on stroke prevention therapy in patients with atrial fibrillation: the atrial fibrillation investigators. Stroke 2009;40:1410-6.

39. Garwood CL, Corbett TL. Use of anticoagulation in elderly patients with atrial fibrillation who are at risk for falls. Ann Pharmacother 2008;42:523-32.

40. Scowcroft AC, Lee S, Mant J. Thromboprophylaxis of elderly patients with AF in the UK: an analysis using the General Practice Research Database (GPRD) 2000-2009. Heart 2013;99:127-32.

41. Benjamin EJ, Wolf PA, D'Agostino RB, et al. Impact of atrial fibrillation on the risk of death: the Framingham Heart Study. Circulation 1998;98:946-52.

42. Stewart S, Hart CL, Hole DJ, et al. A population-based study of the long-term risks associated with atrial fibrillation: 20-year follow-up of the Renfrew/Paisley study. Am J Med 2002;113:359-64.

43. Baglin TP, Cousins D, Keeling DM, et al. Safety indicators for inpatient and outpatient oral anticoagulant care: [corrected] Recommendations from the British Committee for Standards in Haematology and National Patient Safety Agency. Br J Haematol 2007;136:26-9.

44. Herrett E, Thomas SL, Schoonen WM, et al. Validation and validity of diagnoses in the General Practice Research Database: a systematic review. Br J Clin Pharmacol 2010:69:4-14. 